\title{
Sistem Pendukung Keputusan Penentuan Tim Helpdesk UNBK Menggunakan Metode Analytical Hierarchy Process
}

\author{
Teuku Mufizar ${ }^{1}$, Sarmidi ${ }^{2}$, Mira Yuliani ${ }^{3}$ \\ ${ }^{1,3}$ Teknik Informatika STMIK Tasikmalaya, Jl RE Martadinata No. 272 A Kota Tasikmalaya 46151, Indonesia \\ ${ }^{2}$ Komputer Akuntansi STMIK Tasikmalaya, Jl RE Martadinata No. 272A Kota Tasikmalaya 46151, Indonesia \\ e-mail: fizargama@gmail.com¹,sarmidi@stmik-tasikmalaya.ac.id²,mirayuliani5@gmail.com³
}

\section{INFORMASI ARTIKEL}

\section{Sejarah Artikel:}

Diterima Redaksi : 18 April 2020

Revisi Akhir : 26 Juli 2020

Diterbitkan Online : 06 Agustus 2020

\section{Kata Kunci :}

SPK, Tim Helpdesk, UNBK, AHP

\section{Korespondensi :}

Telepon / Hp : +62 85223552929

E-mail : fizargama@gmail.com

\section{A B S T R A K}

Tim Helpdesk UNBK memiliki peran penting sebagai pusat layanan penanganan apabila terjadi masalah bagi sekolah pada saat berlangsung UNBK. Penentuan Tim Helpdesk UNBK saat ini belum menggunakan aplikasi komputer dan proses penyeleksiannya masih bersifat subyektif yang memungkinkan ketidaktepatan dari calon yang terpilih. Maka dari itu dibangun sistem peyeleksian dengan menggunakan metode analytical hierarchy process (AHP) yang menggunakan konsep perbandingan antara satu kriteria dengan kriteria lainnya. Kriteria yang digunakan pada penelitian ini adalah pengetahuan TIK, pengalaman proktor, sertifikat IT, komunikasi,disiplin, dan tanggung jawab. Hasil akhir dari penelitian ini berupa rekomendasi calon tim helpdesk UNBK yang paling layak serta kompeten sesuai dengan yang dibutuhkan. Dari 5 calon sebagai kandidat, terpilih 3 urutan teratas yang telah diuji melalui perhitungan manual dan dibandingkan dengan hasil dari aplikasi komputer menunjukkan hasil yang sama, yaitu Ude Sony Senjaya, Yayat Suhayat, dan M Imam.

\section{PENDAHULUAN}

UNBK (Ujian Nasional Berbasis Komputer) disebut juga Computer Based Test (CBT) adalah sistem pelaksanaan ujian nasional dengan menggunakan komputer sebagai media ujiannya. Untuk kelancaran pelaksanaan UNBK, terdapat beberapa stakeholder yang memiliki peranan masing-masing yakni ; Tim Teknis UNBK, Tim Helpdesk, Proktor, Teknisi dan Pengawas Ujian [1].

Tim Helpdesk UNBK merupakan pusat layanan penanganan masalah bagi sekolah yang mengikuti Ujian Nasional Berbasis Komputer (UNBK) yang memberikan informasi dan penjelasan terhadap pertanyaan atau pengaduan yang diterima dari Pengawas, Proktor dan Teknisi. Tim Helpdesk memiliki beberapa tingkatan yaitu; tingkat pusat, tingkat provinsi dan tingkat kabupaten/kota.

Namun, terdapat kendala dalam penentuan tim Helpdesk di beberapa Kabupaten atau Kota yakni proses penentuannya dilakukan dengan cara dipilih langsung oleh Panitia UNBK Tingkat Kabupaten atau Kota tanpa adanya sebuah proses penyeleksian berdasarkan kriteria-kriteria. Dengan kondisi tersebut dimungkinkan tim Helpdesk Tingkat Kabupaten/Kota ialah orang-orang yang belum bisa dipastikan kemampuannya dalam menjalankan tugasnya, sehingga dapat menghambat pelaksanaan UNBK ketika ada Proktor atau Teknisi yang mendapatkan kendala atau masalah pada saat UNBK berlangsung.

Oleh karena itu, perlu adanya sebuah sistem pendukung keputusan yang akan menentukan kelayakan untuk menjadi Tim Helpdesk Tingkat Kabupaten atau Kota berdasarkan kriteria-kriteria. Adapun kriteria- kriteria yang akan diterapkan pada penelitian ini adalah; pengetahuan mengenai TIK, pengalaman menjadi proktor, sertifikat IT, komunikasi, disiplin dan tanggungjawab.

Untuk membangun sistem tersebut digunakan metode Analytical Hierarchy Process (AHP) yang merupakan salah satu metode dalam sistem pendukung keputusan yang memiliki keunikan di bandingkan yang lainnya[2]. Dasar berpikirnya metode AHP adalah proses membentuk skor secara numerik untuk menyusun rangking setiap alternatif keputusan berbasis pada bagaimana sebaiknya alternatif itu dicocokkan dengan kriteria pembuat keputusan. [3]

Beberapa referensi terkait penelitian ini yaitu pertama penelitian berjudul "Sistem Pendukung Keputusan Menentukan Teknisi Mesin EDC (Electronic Data Capture) terbaik menggunakan Metode Analytical Hierarchy Process (Studi Kasus: PT. Souci Indoprima" oleh Ari Chandra Kirana [4]. Hasil dari penelitian ini yaitu dengan adanya SPK dapat mendukung proses penentuan teknisi yang lebih berkualitas, transparan, cepat serta tersedianya basis data bagi PT. Souci Indoprima.

Referensi kedua yaitu "Sistem Pengambilan Keputusan untuk Pemilihan Teknisi Lab dengan multi kriteria menggunakan Metode AHP (Analytical Hierarchy Process)" oleh Andri Suryadi dan Dian Nurdiana[5]. Kesimpulan dari penelitian ini yaitu dengan menggunakan sistem pengambilan keputusan ini proses perekrutan menjadi optimal.

Referensi ketiga yang berjudul "Implementasi Metode Profile Matching dengan Weighted Product pada Seleksi Staf Operator Komputer ( Studi Kasus: UPTD Pendidikan Kecamatan Tambakboyo Kabupaten 
Tuban Jawa Timur)" oleh Oktavianis Kartikasari, Nurul Hidayat dan Suprapto [6]. Hasil akhir dari yang penelitian ini yaitu hasil pengujian yang dilakukan yaitu pengujian akurasi adalah $80 \%$ dimana jumlah peringkat yang sama antara hasil sistem dan hasil seleksi staf operator komputer adalah 21 data.

\section{METODOLOGI}

Alur penelitian metode AHP dalam penentuan Tim Helpdesk UNBK bisa dilihat di gambar 1.

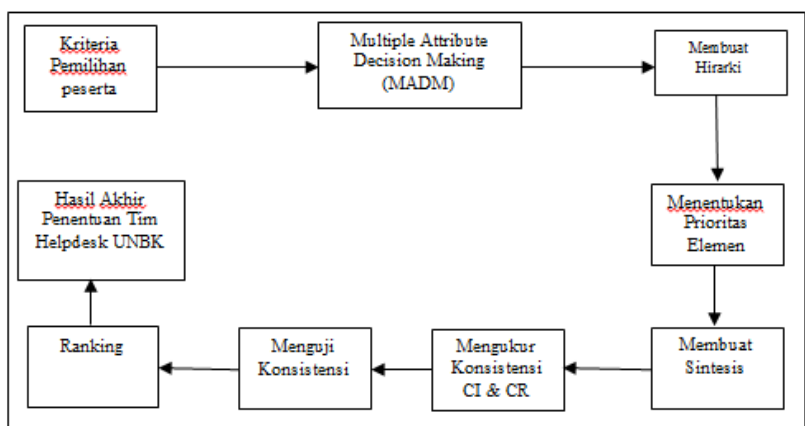

Gambar 1. Alur penelitian dengan metode AHP dalam penentuan

Tim Helpdesk UNBK

Secara umum langkah-langkah yang harus dilakukan dalam menggunakan AHP untuk pemecahan suatu masalah adalah sebagai berikut [7][8]:

1. Mendefinisikan masalah dan menentukan solusi yang diinginkan, lalu menyusun hierarki dari permasalahan yang dihadapi.

2. Menentukan prioritas elemen

3. Membuat Sintesis

4. Mengukur Konsistensi

5. Hitung Consistency Index (CI) dengan rumus: $\mathrm{CI}=$ $\frac{(\lambda \mathrm{maks}-\mathrm{n})}{(n-1)}$

Dimana $\mathrm{n}=$ banyaknya elemen

6. Hitung Rasio Konsistensi/Consistency Ratio (CR) dengan rumus:

$$
\mathrm{CR}=\frac{C I}{R I}
$$

Dimana $\mathrm{CR}=$ Consistency Ratio

$\mathrm{CI}=$ Consistency Index

$\mathrm{RI}=$ Random Indeks Consistency

7. Memeriksa konsistensi hierarki.

\section{HASIL DAN PEMBAHASAN}

\subsection{Analisis perhitungan metode AHP}

Dalam metode AHP terdapat kriteria yang dibutuhkan untuk proses perhitungan. Untuk kasus penentuan tim helpdesk UNBK ini terdapat 6 kriteria yang akan digunakan yaitu :
1) Pengetahuan TIK
2) Pengalaman Proktor
3) Sertifikat IT
4) Komunikasi
5) Disiplin
6) Tanggung Jawab

Nilai untuk kriteria pengetahuan TIK, komunikasi, disiplin, dan tanggung jawab diperoleh dari hasil tes dan wawancara oleh panitia (lihat tabel 1). Nilai untuk Pengalaman proktor diperoleh dari pengalamanya menjadi proktor (lihat tabel 2). Nilai untuk kriteria sertifikasi IT diperoleh dari jenis pelatihan yang telah diikuti yang dibuktikan dengan Sertifikat IT (lihat tabel $3)$.

Tabel 1. Nilai Kriteria Pengetahuan TIK, Komunikasi, Disiplin, dan Tanggung Jawab

\begin{tabular}{cc}
\multicolumn{2}{c}{ Tanggung Jawab } \\
\hline nilai & keterangan \\
\hline$>=85$ & Sangat baik \\
$75-84$ & baik \\
$65-74$ & cukup \\
$<65$ & kurang \\
\hline
\end{tabular}

\begin{tabular}{cc} 
Tabel 2. Nilai Kriteria Pengalaman Proktor \\
\hline pengalaman & keterangan \\
\hline$>3$ kali & sangat baik \\
3 kali & baik \\
2 kali & cukup \\
1 kali & kurang \\
\hline
\end{tabular}

Tabel 3. Nilai Sertifikat Keahlian IT

\begin{tabular}{cc}
\hline tingkat & jenis sertifikat \\
\hline 1 & CCENT (Cisco Certified Entry Networking Technician) \\
2 & CCNA (Cisco Certified Network Associate) \\
3 & CCNP (Cisco Certified Network Profesional) \\
4 & CCIE (Cisco Certified Internetwork Eksport) \\
5 & CCAr (Cisco Certified Architect) \\
\hline
\end{tabular}

Langkah selanjutnya dilakukan penilaian perbandingan antara satu kriteria dengan kriteria yang lainnya. Kemudian jumlahkan setiap nilai tersebut berdasarkan kriteria perkolomnya (lihat tabel 4).

Tabel 4. Hasil Perbandingan kriteria

\begin{tabular}{lcccccc}
\hline \multicolumn{1}{c}{ kriteria } & p.tik & p.p & s.it & $\mathbf{k}$ & $\mathbf{d}$ & $\mathbf{b j}$ \\
\hline penget. tik & 1 & 1 & 3 & 4 & 7 & 7 \\
pengal. proktor & 1 & 1 & 3 & 4 & 7 & 7 \\
sertifikat it & 0,33 & 0,33 & 1 & 2 & 5 & 5 \\
komunikasi & 0,25 & 0,25 & 0,50 & 1 & 4 & 4 \\
disiplin & 0,14 & 0,14 & 0,20 & 0,25 & 1 & 1 \\
bertnggng jwb & 0,14 & 0,14 & 0,20 & 0,25 & 1 & 1 \\
\hline jumlah & 2,87 & 2,87 & 7,90 & 11,5 & 25 & 25 \\
\hline
\end{tabular}

Selanjutnya melakukan langkah-langkah untuk menghitung matriks nilai kriteri, menentukan prioritas, matriks penjumlahan setiap baris dan perhitungan rasio konsistensi. Kemudian dilakukan juga perhitungan prioritas subkriteria dari semua kriteria (pengetahuan tik, pengalaman proktor, sertifikat IT, komunikasi, disiplin, dan tanggung jawab). Prioritas hasil perhitungan pada langkah tersebut diatas kemudian dituangkan dalam matriks hasil yang terlihat pada tabel 5 . 
Tabel 5. Matriks Hasil

\begin{tabular}{cccccc}
\hline $\begin{array}{c}\text { penget } \\
\text { tik }\end{array}$ & $\begin{array}{c}\text { peng. } \\
\text { proktor }\end{array}$ & $\begin{array}{c}\text { sertifikat } \\
\text { it }\end{array}$ & komunikasi & disiplin & $\begin{array}{c}\text { tanggung } \\
\text { jawab }\end{array}$ \\
\hline 0,33 & 0,33 & 0,16 & 0,11 & 0,04 & 0,04 \\
$\begin{array}{c}\text { Sangat } \\
\text { Baik }\end{array}$ & $\begin{array}{c}\text { Sangat } \\
\text { Baik }\end{array}$ & CCAr & Sangat Baik & $\begin{array}{c}\text { Sangat } \\
\text { Baik }\end{array}$ & $\begin{array}{c}\text { Sangat } \\
\text { Baik }\end{array}$ \\
1 & 1 & 1 & 1 & 1 & 1 \\
Baik & Baik & CCIE & Baik & Baik & Baik \\
0,47 & 0,47 & 0,62 & 0,47 & 0,47 & 0,47 \\
Cukup & Cukup & CCNP & Cukup & Cukup & Cukup \\
0,23 & 0,23 & 0,38 & 0,23 & 0,23 & 0,23 \\
Kurang & Kurang & CCNA & Kurang & Kurang & Kurang \\
0,07 & 0,07 & 0,24 & 0,07 & 0,07 & 0,07 \\
& & CCENT & & & \\
& & 0,09 & & & \\
\hline
\end{tabular}

Selanjutnya dibuatkan studi kasus ini diambil lima alternatif calon tim helpdesk UNBK untuk di seleksi dengan menggunakan metode AHP, seperti terlihat pada tabel 6 .

Tabel 6. Nilai Alternatif/Calon Helpdesk UNBK

\begin{tabular}{lcccccc}
\hline \multicolumn{1}{c}{ alternatif } & $\begin{array}{c}\text { penget. } \\
\text { tik }\end{array}$ & $\begin{array}{c}\text { pengal. } \\
\text { proktor }\end{array}$ & $\begin{array}{c}\text { sertifikat } \\
\text { it }\end{array}$ & $\begin{array}{c}\text { komuni- } \\
\text { kasi }\end{array}$ & $\begin{array}{c}\text { Disi- } \\
\text { plin }\end{array}$ & $\begin{array}{c}\text { tanggung } \\
\text { jawab }\end{array}$ \\
\hline $\begin{array}{l}\text { Ude Sony } \\
\text { Senjaya }\end{array}$ & 85 & 2 & CCNA & 72 & 75 & 75 \\
$\begin{array}{l}\text { Irawan } \\
\text { Husni M }\end{array}$ & 86 & 1 & CCENT & 70 & 75 & 75 \\
Farhan & 75 & 2 & CCNA & 85 & 80 & 80 \\
M Imam & 70 & 3 & CCNA & 85 & 85 & 80 \\
$\begin{array}{l}\text { Yayat } \\
\text { suhayat }\end{array}$ & 90 & 2 & CCENT & 70 & 75 & 75 \\
\hline
\end{tabular}

Hasil akhir dari perhitungan metode AHP ini terlihat pada tabel 7 berikut.

Tabel 7. Hasil Akhir Perhitungan

\begin{tabular}{lccccccc}
\hline altern & $\begin{array}{c}\text { pen } \\
\text { atif } \\
\text { get. } \\
\text { tik }\end{array}$ & $\begin{array}{c}\text { peng } \\
\text { al. } \\
\text { prok } \\
\text { tor }\end{array}$ & $\begin{array}{c}\text { sertifi } \\
\text { kasi it }\end{array}$ & $\begin{array}{c}\text { kom } \\
\text { uni } \\
\text { kasi }\end{array}$ & $\begin{array}{c}\text { disip } \\
\text { lin }\end{array}$ & $\begin{array}{c}\text { tangg } \\
\text { ung } \\
\text { jawab }\end{array}$ & $\begin{array}{c}\text { juml } \\
\text { ah }\end{array}$ \\
\hline $\begin{array}{l}\text { Ude } \\
\text { sony } \\
\text { senjaya }\end{array}$ & 0,33 & 0,08 & 0,04 & 0,03 & 0,02 & 0,02 & 0,51 \\
$\begin{array}{l}\text { Irawan } \\
\text { Husni }\end{array}$ & 0,33 & 0,02 & 0,01 & 0,03 & 0,02 & 0,02 & 0,43 \\
M & & & & & & & \\
$\begin{array}{l}\text { Farhan } \\
\text { M }\end{array}$ & 0,16 & 0,08 & 0,04 & 0,11 & 0,02 & 0,02 & 0,42 \\
$\begin{array}{l}\text { Imam } \\
\text { Yayat } \\
\text { suhaya } \\
\text { t }\end{array}$ & 0,08 & 0,16 & 0,04 & 0,11 & 0,04 & 0,02 & 0,44 \\
\hline
\end{tabular}

Nilai pada tabel diatas diperoleh dari perkalian antara nilai prioritas dengan nilai prioritas subkriteria pada tabel 5. Seperti nilai 0,33 pada kolom Pengetahuan TIK baris alternatif Ude Sony Senjaya diperoleh dari nilai yang didapat untuk pengetahuan TIK yaitu 85 , seperti yang sudah dijelaskan di atas bahwa nilai 85 temasuk kedalam kategori 'Sangat Baik' (lihat tabel 1), maka menghasilkan nilai prioritas sub kriteria yaitu 1 (lihat tabel 5), kemudian dikalikan dengan nilai kriteria
Pengetahuan TIK yaitu 0,33 , sehingga hasilnya yaitu 0,33 .

Selanjutnya nilai pada kolom jumlah pada tabel 7 atas diperoleh dari penjumlahan pada masing - masing barisnya. Nilai total inilah yang dipakai sebagai dasar untuk merangking calon tim helpdesk UNBK. Semakin besar nilainya, maka calon tim helpdesk itulah yang akan terpilih. Berdasarkan tabel diatas, maka apabila akan diambil 3 orang yang terpilih menjadi Tim Helpdesk UNBK tingkat Kabupaten, maka hasilnya bisa dilihat pada tabel 8 .

\begin{tabular}{clc}
\multicolumn{3}{c}{ Tabel 8. Hasil Perangkingan } \\
\hline rangking & \multicolumn{1}{c}{ nama } & hasil akhir \\
\hline 1 & Ude Sony Senjaya & 0,51 \\
2 & Yayat Suhayat & 0,48 \\
3 & M Imam & 0,44 \\
\hline
\end{tabular}

\subsection{Implementasi Sistem}

Pada bagian ini dibangun sistem dengan mengikuti tahapan System Developtmeny Life Cycle (SDLC) [9][10]. Berikut ini ditampilkan antar muka (interface) aplikasi dari sistem yang telah dibuat . Pada gambar 2 terlihat tampilan untuk masuk kedalam aplikasi. Pengguna melakukan login dengan mengisi username dan password yang benar. Jika benar maka akan dialihkan ke halaman utama (lihat gambar 3). Dalam halaman utama terdapat beberapa menu, yaitu menu input data, menu analisa data, admin area.
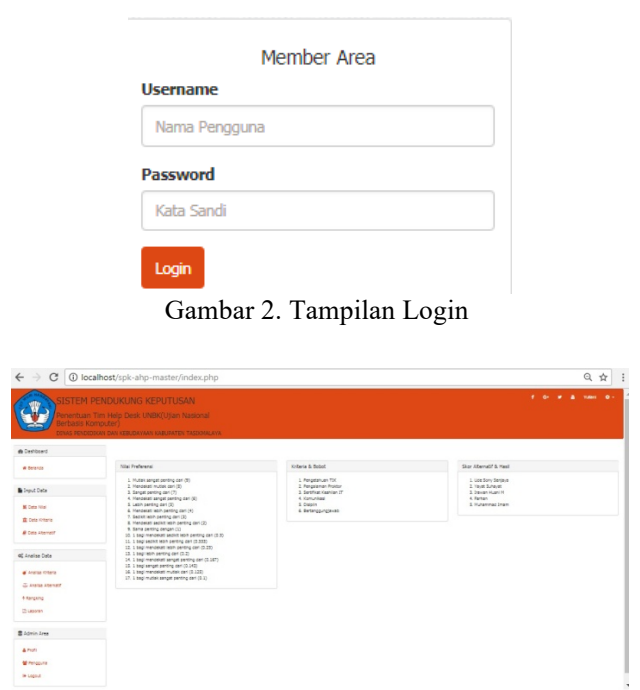

Gambar 3. Tampilan Halaman Utama

Selanjutnya pada gambar 4 menampilkan halaman data nilai kriteria untuk menginputkan data untuk kriteria yang digunakan.

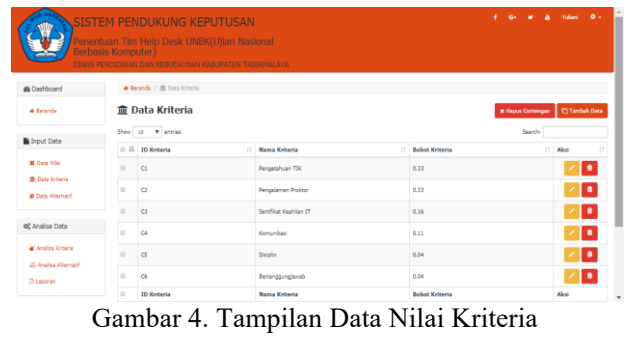


Pada gambar 5 menampilkan halaman untuk melihat dan menginputkan data alternatif atau data calon yang akan diseleksi.

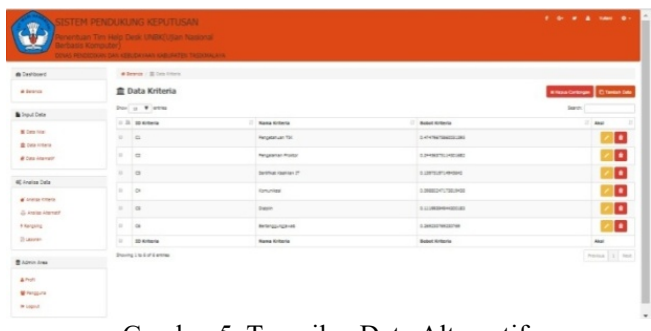

Gambar 5. Tampilan Data Alternatif

Pada gambar 6 terlihat halaman untuk proses perbandingan antara kriteria satu dengan kriteria yang lainnya. Selanjutnya dilakukan proses perhitungan berdasarkan kriteria yang telah dibandingkan dengan metode AHP (lihat gambar 7)
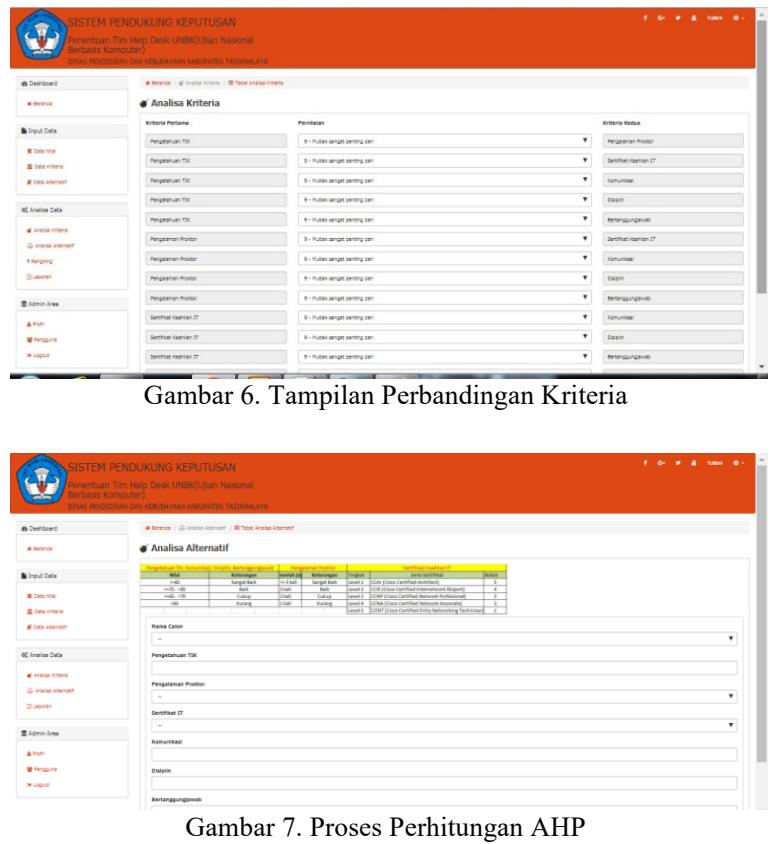

Terakhir, pada gambar 8 terlihat hasil akhir berupa perangkingan dari calon/alternatif yang memiliki nilai tertinggi sampai terendah dan akan dinyatakan sebagai kandidat terpilih pada proses penentuan Tim helpdesk UNBK. Terlihat hasil yaitu dari 5 alternatif, terpilih 3 teratas yaitu : Ude Sony Senjaya, Yayat Suhayat, dan M Imam.

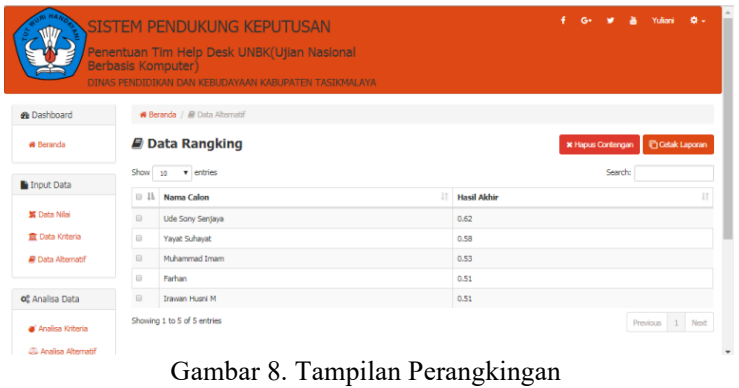

\section{KESIMPULAN}

Kesimpulan akhir dari penelitian ini yaitu dengan dibangunnya sistem pendukung keputusan penentuan Tim Helpdesk UNBK menggunakan metode Analytical Hierarchy Process (AHP) dan kriteria-kriteria yang telah ditetapkan dapat menghasilkan rekomendasi calon Tim Helpdesk UNBK yang paling layak serta kompeten sesuai dengan yang dibutuhkan sehingga dapat meminimalisir kurang tepatnya pengambilan keputusan. Selain itu didapatkan data pengujian dari 5 calon sebagai kandidat, terpilih 3 urutan teratas yang telah diuji melalui perhitungan manual dan dibandingkan dengan hasil dari aplikasi komputer menunjukkan hasil yang sama, yaitu Ude Sony Senjaya, Yayat Suhayat, dan M Imam.

\section{DAFTAR PUSTAKA}

[1] POS Ujian Nasional Berbasis Komputer. 2018.

[2] T. Mufizar, D.S. Anwar, dan R.K. Dewi. "Pemilihan Calon Penerima Bantuan Siswa Miskin Menggunakan Metode Analytical Hierarchy Process (AHP)." Creative Information Technology Journal, Volume 4, Nomor 1, Tahun 2016, Hal : $30-44$.

[3] D. Nofriansyah, dan S. Defit. “ Multi Criteria Decision Making (MCDM) Pada Sitem Pendukung Keputusan", Yogyakarta : CV Budi Utama, 2017

[4] A.C. Kirana, "Sistem Pendukung Keputusan Menentukan Teknisi Mesin EDC (Electronic Data Capture) Terbaik Menggunakan Metode Analytical Hierarchy Process (Studi Kasus : PT. Souci Indoprima)", Pelita Informatika Budi Darma, Volume : IX, Nomor: 3, 2015, ISSN : 2301-9425.

[5] A. Suryadi, dan D. Nurdiana, "Sistem Penunjang Keputusan Untuk Pemilihan Teknisi Lab Dengan Multi Kriteria Menggunakan Metode AHP (Analytical Hierarchy Process)", Jurnal Pendidikan Matematika, Volume 5, Nomor 1, April 2015, ISSN 2086-4299.

[6] O. Kartikasari, N. Hidayat, Suprapto, "Implementasi Metode Profile Matching Dengan Weighted Product Pada Seleksi Staf Operator Komputer (Studi Kasus : UPTD Pendidikan Kecamatan Tambakboyo Kabupaten Tuban Jawa Timur)", Jurnal Pengembangan Teknologi Informasi dan Ilmu Komputer e-ISSN : 2548-964X Vol.1, No. 11, hlm. 1331-1336, November 2017

[7] Kusrini, "Konsep Dan Aplikasi Sistem Pendukung Keputusan”. Yogyakarta: Andi Offset, 2007

[8] D. Nofriansyah dan S. Defit, "Multi Criteria Decision Making (MCDM) pada Sistem Pendukung Keputusan", Deepublish, 2017.

[9] K.E. Kendall and J.E. Kendall, "Systems Analysis and Design 8th Edition", Prentice Hall, 2010

[10] A. Dennis et al, "Systems Analysis and Design with UML 5th Edition", John Wiley and Sons, 2016 